\title{
RELATIONSHIPS BETWEEN MAN AND MACHINE PONDERING UNDERLYING ASSUMPTIONS AND THEIR CONSEQUENCES FOR USERS
}

\author{
Hans Olav Omland \\ Institute of information systems, University of Agder, Norway
}

\begin{abstract}
The handling of an expected pandemic (covid-19), though with surprizing consequences, creates a dilemma in what to prioritize, stated simply: lives or economy? The rapid spread of Internet, Social Media, Artificial Intelligence, and millions of apps seem to be less surprising even though critical voices have for long raised concerns about the consequences of this internet based 'pandemic'. Enterprises develop their own information systems without necessarily explicating their strategies and what models the systems build on. The uncertainties of what is inside the systems, how collected data is handled and used, along with the consequences of use in short and long-time perspective are therefore up for ethical considerations presenting us with a dilemma, a social dilemma. The spread of all kinds of applications has taken place basically in the lawless virtual country Internet with very few if any regulations of content. We therefore question what considerations are made on the relationships between users and technology. We use Buber's 'I-You'/'I-It' model analysing relationships between man and machine analyse data about Facebook, Amazon and Google/Google Chrome including Artificial Intelligence. We find that development and deployment decisions of internet-based apps are made based on values unknown to the users and that there is a lack of ethical standards which makes it difficult to draw ethical conclusions. With few laws governing the lawless land Internet the future of the relationships between humans and machines is open to exploitation from any actor that is able to provide the means needed presenting a choice between lives and economy?
\end{abstract}

\section{KEYWORDS}

Information Systems Development, Modelling, Relationships, Ethics, Humans

\section{INTRODUCTION}

Deploying inventions may change humans and societies. Even if people printed before Gutenberg, he was the first European to use movable type for printing. However, his most important contribution was the perfection of the printing process and the possibilities to correct errors easily. The availability and use of his invention changed Europe. In 1844 Samuel Morse sent the first telegram from Washington to his partner Alfred Vail in Baltimore containing the following text "WHAT HATH GOD WROUGHT?". For the first time in human history a message did travel faster than nature made possible. "Amusing ourselves to Death: Public Discourse in the Age of Show Business" (Postman 1985), commenting on show business on TV, suggested that Aldous Huxley's Brave New World, whose public was oppressed by their addiction to amusement, reflected the contemporary world was better than George Orwell's Nineteen Eighty-Four, where they were oppressed by state control.

How do the three inventions, printing, telegrams, and TV relate to the digital inventions of today? The use of the three inventions changed society for better and for worse and are in many ways basic inventions that our society rests on today. Using the inventions changed power structures in society, opened up for more actors, and gave people in general more choices. The inventions were and are used and misused depending on what lens, what values, and what ethical standards used in the considerations.

With the pandemic spread of today's new inventions it may be appropriate to research the relationships between humans and information systems (ISs), their underlying assumptions, and results of applying them for humans. In Chapter 2 we refer theoretical perspectives and foundations while Chapter 3 presents examples of technology that we study. Chapter 4 contains the discussion while Chapter 5 conclude the paper. 


\section{THEORETICAL PERSPECTIVES AND FOUNDATIONS}

What perspective we view IT/IS and its deployment will influence how we understand and analyzes the pandemic spread and use of ISs, also labelled machine, here, as a generic term.

Any invention or development of an IS builds on some basic understanding of the development itself, the IS, and the users of the systems (Iivari et al, 1998) presented and represented by models. However, as no model is reality: What is modelled and how well do the models represent the reality in question and those that must bear the consequences? There is "no silver bullet" (Brooks, 1987). Any IS having its advantages and disadvantages the question is rather: for whom?

One way of approaching an answer is to question: What are the relationships between man and his fellow machines (Sætra, 2019) especially now with the pandemic spread of advancing technology, information systems, and apps? How are the relationships between man and machine modelled in development situations (Nurminen, 1988), and what development methods and methodologies are deployed (Iivari et al, 1998)? Any model of reality has some inbuilt values and underlying assumptions (Iivari et al, 1998).

\subsection{Three Perspectives for Developing Information Systems (Nurminen, 1988)}

Nurminen (1988) raises the question "People or computers?" using three perspectives discussing the relationships between humans and machines when developing ISs, the systems-theoretical perspective, the socio-technical perspective, and the humanistic perspective.

"A factor essential to the behaviour of the system is that of the rules of behaviour of the individual elements" (Nurminen 1988, p. 27). Systems theory is defined as 1) a finite set of distinct (non-overlapping) elements and 2) a finite set of relationships between these elements (Lange 1965 referred in Nurminen 1988, p. 26). An important question will therefore be to exclude or to include human beings in the modelling of the system (Nurminen 1988, p. 55). Furthermore, how to model the human behaviour in a way that serves the purpose of the system and the actors using it especially in the age of advancing AI and AGI?

The socio-technical perspective raised the question: "What is the place of the individual in relation to the system?" (Nurminen, 1988 p. 69) focusing on the relationships between human beings and the information system suggesting that the IS included both human beings and a data system (Nurminen,1988). The modelling in the socio-technical approach had three distinct areas: i) Job design includes individual needs of the employees in addition to pay, ii) Social and technical needs and goals are considered equally important, and iii), focusing on autonomous, self-steering groups, not specialized individual tasks (Bjorn-Andersen, 1980 referred in Nurminen, 1988 p. 73). Modelling the social objectives and the technical objectives separately then joining them in a social-technical alternative considering: the knowledge fit, the psychological fit, the efficiency fit, the task-structure fit, and the ethical fit (Nurminen, 1988).

The challenges in the socio-technical approach are that it may depend or bend too much on the technical side that comes with "That is how these things are done!". Social systems change slowly as each system has its own institutions, challenging the borderline between possible and impossible, but completely different from technological determinism.

"The fundamental dualism between the technical and social system sets up a tension field, in which two basically diverse ways of thinking express different notions of knowledge, of man etc." (Nurminen, $1988 \mathrm{p}$ 99). The socio-technical approach is therefore not consistent and unified, but comes with an inbuild conflict, especially how the notion of man is understood and modelled.

Nurminen (1988) suggests a humanistic perspective where the human being should play a leading role meaning that the system should cater for the individual user placing the user in focus, not tools or technology. "We do not refer to the 'user of the scalpel' but to the 'surgeon"” (Nurminen 1988). What language do we use when referring to the human being in the approaches including the humanistic approach?

The humanistic perspective challenges the notion of human beings in the systems-theoretical approach and the socio-technical view where the human being is seen both as object and subject in the approaches (Nurminen 1988). As long as the two are in equilibrium, there is no problem. But when the equilibrium is challenged and the technical part is heavily weighted "the socio-technical framework becomes a means of manipulation, a tool whereby the workers in the organization can be induced to adapt themselves to changes coming from outside." (Nurminen 1988). In recent times analysing data producing new pieces of information are on the rise where companies use information about information through AI or AGI to reach their own 
goals labelled Surveillance Capitalism (Zuboff 2019). What focus is information systems developed to emphasize? The original purpose of the information system may be useful for the original user, but other foci may be challenging or dangerous for the individual user as $s /$ he do not have control over the use of the data created by them in their original use. What types of systems are developed and used especially in the age of more advanced systems including AI and AGI in the pandemic spread of systems and their use?

\subsection{Relationships between Man and Machine}

Nurminen's (1988) discussion on relationships between man and system is echoed in the relationship between man and machine (Sætra 2019) including the discussion on human artifacts in recent development of ISs like Internet and AI-based systems. Buber (Wodehouse, 1945) suggests two different types or qualities in relationships between humans: 'I-You', depict two subjects that are interacting with each other while in 'I-It', 'I' the subject relates to 'It' as an object, a relationship with an instrumental use of the object.

Humans and machines may form four relationships that have two sub-relationships each either an 'I-You' or an 'I-It'. The character of the each of the relationship may switch, over time, 'I-You' to 'I-It' or vice versa. Before we describe the relationships, an important note from Buber (Wotehouse, 1945):: 'I' am made, 'I' come into existence in relationship to a 'You' (as a human being), while the same is not true in the 'I-It' relationship. We may wonder if an 'I-You' relationship between a human and a machine will bring the machine into existence, and eventually into what kind of existence?

\subsubsection{Relationships between Man and Man}

This relationship may be face-to-face or mediated through machines, PCs, mobile phones or other technology-based equipment. It is not discussed here because it will mediate an undisturbed communication between the two both in the 'I-You' and 'I-It' relationship.

\subsubsection{Relationships between Man and Machine/Machine and Man}

This section operates with man-machine/machine-man to distinguish situations where the first element is the subject, the latter the object. If the relationship between man and machine/machine and man is a 'I-You' relationship, the relationship may fulfill the Turing test communicating through an interface with words only. However, it seems that people developing AI and AGI are optimistic that "all" sides of human life may be present in and communicated with a machine including the physical appearance, mimic, feelings, and other human criteria. The discussion of demarcation of humans (Sætra 2019) then comes in focus. Can the machine be able to fool humans through outwardly appearance, or will the machine need soul and/or selfconsciousness (Sætra 2019)? Humans may have created a machine in its own likeness, possibly without understanding what it means for humans if the machine have characteristics and abilities that precedes human beings. Will the relationship then be an 'I-You' between Man and Machine?

The prevailing relationship between man and machine today and how it is designed points to an 'I-It' relationship. The user, as subject, uses the system to reach objectives for solving his/her tasks and produce data/information without considering the machine as a 'You', in Buber's understanding.

The subcategory where the Machine is an 'I' (subject) and the Man an 'It' (object) raises many questions. What may happen when human beings are treated as objects by a machine? Can the human free him/herself from the machine? What actions may the machine want to take? What kind of ethics does the machine use in its/her/his decisions and executions of the decisions? Today's light version of such systems may be as described in Surveillance Capitalism (Zuboff 2019). Information provided by human users are used, without their knowledge, as data for making business for the companies collecting the data.

What about social media? The machine is actively making decisions, but mostly through preprogrammed algorithms. What would happen if the machine on its, or hers, or his own initiatives start to decide about social media, what to publish or not, how to arrange searches, and what to publish about human behavior in social media? Could we as human beings through the machine - man ('I-It') relationships have created a Frankenstein Monster that controls us?

\subsubsection{Relationships between Machine and Machine}

What might a machine that relates to another machine as 'I-You' mean? Discussing such situations based on today's technology gives no meaning. If 'technology optimists' get the last word, such situations may well 
occur in the future. Will differences in and between machines resemble differences in and between human beings like cognitive abilities, intelligences of many types, behavior, and personalities? If so machine-tomachine relationships may resemble human relationships, power in relationships, and other characteristics of human relationships raising ethical and legal questions in machine-to-machine relationships.

In an 'I-It' machine relationships these considerations will be less challenging if the 'It' machine is not granted a value in itself. However, should machines be subjects in their own appearance, an 'I-It' machine relationship will be instrumental. How could machines decide their own value as subjects, or should that be decided by the other machines in a community of machines?

What may happen when machine to machine relationship result in consequences for humans? When machines in a machine-to-machine relationships make decisions affecting humans, should humans be given the right, the opportunity, and the possibilities to raise their concerns in such situations?

What could possibly happen of innovations and inventions in a machine-to-machine relationship where the machine might be able to foresee possible consequences of the inventions? Would the machines then let go of the inventions or would the machines use inventions and innovations as we humans often do to get power or some kinds of benefits? How would machines handle such dilemmas?

\subsection{Meaning of Communication}

Any relationship is dependent on communication. It is important to understand communication as something more than just words. Aspects of communication relate to the spiral of collaboration where communication have four functions relating to each other: 1) The social function, 2) The expressive function, 3) The information function, 4) The control function (Thunberg et al. 1982 referred in Nurminen $1988 \mathrm{p} \mathrm{137).}$

When these four functions "are successfully combined in a well-balanced whole, the conditions are at the same time created for the spiral of collaboration." (Nurminen, 1988, p 137). If collaboration improves it turns into a positive spiral of Identity, Community, Knowledge, and Action (Nurminen 1988 p 138) where these four areas are widening and increasing the collaboration. The elements Information and Action are widely discussed and emphasised in ISD. The element of Identity relates to the human being and may answer questions like "Who am I?" and "What is my limits?" (Nurminen, 1988). The element of Community is maybe least discussed of these four elements even if ISD is a collective action. Even if use of information systems often is individual, collective actions are needed to provide a good result for an organization. Social media, furthermore, have as a core idea to create community or at least a feeling of community for the users.

Earlier discussions on relationships between man and machine has often seen machine as an artefact, a man-made tool. However, as human beings are continuing to develop the machines, especially related to AI and even more to AGI, "the demarcation of man is a difficult task, .. " (Sætra 2019 p. 226) and will influence how we may understand communication between man and machine. Concluding the discussion on "The elusive boundary between man and machine" Sætra (2019) states that "If we, for the sake of argument, are to exclude supernatural qualities that separate man from other beings, what is the criterion for the demarcation? “ (p. 225). Sætra (2019) dismisses the criterion of life and biology as we share that with other beings. However, artificial beings are already capable to imitate life from human life. As for mental superiority machines surpasses us in certain areas as computing, remembering etc. while turning to emotions or morality these aspects of life are suggested to be imitated in "increasingly true-to-life ways by machines." (Sætra 2019 p. 226). However, “There's No Such Thing As 'Ethical A.I."' (Chatfield 2020).

Considering consciousness as a candidate is just as elusive concept as the concept of a soul (Sætra 2019) and therefore difficult or impossible to relate to this research. "Of course, one can't dismiss everything not directly observable, but in search of acceptable criteria, it would be good if one could find something all could agree on" (Sætra 2019 p. 226).

"Alternatively, one might decide that only Homo sapiens are moral agents, but this seems rather arbitrary." (Sætra, 2019 p. 226). No discussion about the suggestion of arbitrary is provided. No matter what criteria we as Homo sapiens choose for the relationships between man and machine, the criteria chosen will have many consequences for the further development of machines and for us as the human race. Humans are curious, ingenious, inventive, and our desire to create may lead to "problems for the creator" (Sætra, $2019 \mathrm{p}$. 226). The innovation of the nuclear bomb may be one example. Nurminen (1988) and Sætra (2019) are both discussing the relationship between man and machine. The understanding of man and of machine will influence how these are modelled when developing information systems and machines. The discussion of 
demarcation of man related to the machine is therefore of vital importance even more so with the possibilities of the Information Panopticon (Zuboff, 1998) and Surveillance Capitalism (Zuboff 2019) opening for machines to observe humans, human actions, and making decisions based on data from the observations.

This research therefore tries to answer the following research question: What challenges may development and deployment of information systems including AI and AGI pose to the relationships between humans and machine?

\section{EXAMPLES}

In this section we present some examples of technology in a wide sense and the use of it.

\subsection{Facebook}

Facebook has been a great, pandemic success. How did Facebook model the user? "Facebook takes advantage of "vulnerability in human psychology"" (Parker, 2017). Early investor and founder, Sean Parker, played an important role in design and marketing of Facebook. He warns about unknown societal consequences of widespread use of social media revealing the intentional modelling and implementation of the technology used by Facebook, designing their systems to keep users on the webpages for as long possible. This was for long unknown to the users.

Former Facebook VP, Chamath Palihapitiya, vice president for user growth, says to reporter Wang in Washington Post that "social media is destroying society with "dopamine-driven feedback loops" (Wang, 2017). Palihapitiya (in Facebook from 2007 - 2011) speaks about his "tremendous guilt" over growing the social network. As the use of Facebook exploded, he reflects on the consequences: "It literally is a point now where I think we have created tools that are ripping apart the social fabric of how society works. That is truly where we are," he said. "The short-term, dopamine-driven feedback loops that we have created are destroying how society works: no civil discourse, no cooperation, misinformation, mistruth. And it's not an American problem. This is not about Russian ads. This is a global problem." (Wang, 2017). With the aim of attracting users, Facebook used mechanisms that according to Palihapitiya have counterproductive effects on creating positive relationships between people. Would Facebook, social media, and Internet in the end devour its own children, maybe not physically, but flatten its users mentally and spiritually?

Chris Cox (2019), a top manager, set up to take over the company if Mark Zuckerberg were to leave, left Facebook in March 2019 after 13 years in the company. He wrote: "For over a decade, I've been sharing the same message that Mark and I have always believed: Social media's history is not yet written, and its effects are not neutral. It is tied up in the richness and complexity of social life. As its builders, we must endeavour to understand its impact - all the good, and all the bad — and take up the daily work of bending it towards the positive, and towards the good. This is our greatest responsibility," His reason for leaving seems to be a disagreement over Zuckerberg's manifesto about privacy that outlined a new direction for the company where the messages should be encrypted and that there should be an interoperability of all the message platforms that Cox oversaw. The interoperability might give Facebook a Panopticon view of the users and the privacy, encryption, may prove a vehicle for hiding illegal activities from police and other authorities making possible great harm to society.

The naïve belief that Internet would promote democracy, by allowing every voice to be heard, may be one of the reasons for the success of Facebook and the 'pandemic' spread. This naïve belief, however, is strange as every newspaper has an Editor in chief responsible for its content, and every publisher of books have editors that have to shoulder responsibilities for what is published, while social media managed to get away with no editor, or no one to be held responsible. In these days where appearance trumps facts, feelings are more important than facts, and some people suggest that the demon lives in the PC, Facebook seems to get by without a responsible editor. 


\subsection{Amazon}

"Jeff Bezos is now worth more than $\$ 200$ billion, making him the richest person in the world by nearly $\$ 90$ billion." (Canales and Sonnemaker, 2020). Bezos has been a very successful entrepreneur and businessman. It seems that the covid-19 pandemic has helped lifting the value of Amazon, but there are obviously more reasons for the success than the covid-19 pandemic. Amazon is totally dependent on technology. It is therefore reasonable to say that their business strategy and their use of technology must be intertwined, and that the technology is used to promote the business strategy and the business processes of the company. It may also be reasonable to state that the strategy promotes the value and business of Amazon without considering the buyers apart from easy ordering and delivery. Discussions on the life qualities of the buyers are not considered for more than the immediate satisfaction of the ease of buying and get the gods delivered.

Amazon use data for producing data to make shopping easier for their customers. At the same time, it may create "echo-chambers" since many of the users will get the same information and Amazon may thereby consciously or unconsciously influence peoples purchases.

\subsection{Google and Google Chrome}

Google has managed to maneuver itself into a hegemonic position amongst browsers and search engines having developed a very efficient search engine. As all activity using the browser is registered, Google collects enormous quantities of data. Using information from the users to produce information for sale Google had the possibilities to extract data for profit. Google gets a very good understanding of movements on internet and is therefore able to analyze patterns amongst users and to a certain degree foresee what users may do. Such data may be useful for organizations to offer goods and services to Google users at opportunistic points of time. The data may also be used for add-on sales in shops where the text "The buyer of this item also bought the following items" or showed interest in the following information.

A questionable function with Google is that Google will not deliver the same search results for the same search words used in different countries/places in the world. By tailoring its search results depending on place of search Google may, dynamically, influence what information is available to the users, and thereby influence peoples' understanding, attitudes, and actions in ways the users are not conscious of, or wanting, or agreeing on.

In the above presentation of Google, the negative sides have been emphasized. The possibilities for searching for information through Google is of course an enormous advantage for many people. Therefore presentation Google in a balanced way is difficult. A major challenge is that people see the good sides of Google's services and downplay or oversee the negative sides of the browser and search engine.

The above examples show that the technology in itself, the use of the technology, and the algorithms in the systems, not known to the users, seem to be for the advantage of the organizations. Furthermore, the companies mentioned are great producers and sellers of secondary data from the original data, often without those who created the data have any understanding of the secondary use.

\section{ANALYSIS AND DISCUSSION}

From the above examples we can observe some occurrences for the three companies:

- Provide useful services to their users

- $\quad$ Are totally dependent on technology and use technology actively for promoting services

- $\quad$ Try to attract and keep users on their websites

- Turn data to sellable products to foresee what users would do in future contact with companies

- Manipulate data to increase their profit

- Conceal or do not let users know fully what data and how data about users are used

All the above companies base their systems on some assumptions of human beings (Iivari et al., 1998) and some models of human actors (Nurminen, 1988). The models have not been open and visible to the users but has secured the companies possibilities to profit. The systems fulfil all the functions of communication (Thunberg et al, 1982, referred in Nurminen, 1988, p 138). However the fulfilment comes with a cost for the users where the user is producing data that they also are consuming. Besides fulfilling all the functions of the 
users the companies mentioned milk their users for information that is sold behind the users' back. The buyers of the information and possible excess information may use the data to predict what the users may do next and advertisements fitting the anticipated situation as surveillance capitalism (Zuboff 2019).

All these occurrences influence the relationships between man and machine. Based on the above we propose a relationship model (cf. Table 1) expanding Buber's model. Buber's relationships were formed in a time when the technology was just transmitting messages back and forth. Today's communication technology is able to influence the communication through compute and/or manipulate data and present data in a communication situation. Mediating the communication in the relationships may be done by computers that are programmed or set up to reframe or reformulated messages based on assumptions of what the user is interested in, or what the mediator wants to communicate.

Table 1. The expanded relationships model (↔ means 'communicates with')

\begin{tabular}{|r|c|c|c|c|}
\hline Human (1) & $\leftrightarrow$ & Machine (1) & $\leftrightarrow$ & Human (2) \\
\hline & & Communicates with & & \\
\hline Human (3) & $\leftrightarrow$ & Machine (2) & $\leftrightarrow$ & Human (4) \\
\hline
\end{tabular}

The machine is modeled and programmed to fulfil communication needs (Thunberg et al, 1982, referred in Nurminen, 1988, p 138), at the same time it is dopamine-driven (Wang, 2017), utilizing user data to influence the users. In such situations the relationships may be felt as an 'I-You' relationship from the user's perspectives while it is a 'I-It' relationship from the machine's perspective and from the other actors in the communication setup. We therefore suggest an expanded relationship model (cf. Table 1) seeking to explain what might happen. This model may be used both in synchronous and asynchronous communication.

The first line in Table 1 shows communication between Human (1) and Human (2) mediated by Machine (1). The machines (1) and (2) may communicate with each other to analyze and decide what to feed back to the user. The lower line is showing the possibilities for the company that provides the service Human (3) while Human (4) depicts the company that wants get help to influence the user, Human (1). Even if the user, Human (1) experiences the relationship as an 'I-You' relationship, the other human actors may have a 'I-It' relationship to the user Human (1) through the machines. What may happen if Human (1) discover that?

In the above model the machines are supposed to be treated as an 'It' from the human side of the relationships. However, if the machines are becoming more humanlike by utilizing AI og AGI or other future technologies, the relationships between the elements in the model will be immensely more complicated. It may or will be difficult for humans to know or identify, or foresee, or react properly to the communication with the machines especially if it is difficult to distinguish the machine's reactions from human reactions. What may happen then to humans experiencing decisions made by the machine?

On the positive side, however, in some situations, the objective of the systems is to collect information to produce information that may be useful for i.e., treatment of a person. In such situations there may be a mutual understanding in the relationship that this is the objective of the system and a useful thing. In the end the dilemma exists in that the system including humans and machines may be very useful for solving difficult situations, while in other situations the machine may take control of the humans and make them play a secondary role in their own lives. What could possibly happen of innovations and inventions in a machine-to-machine relationship where the machine might be able to foresee possible consequences of the inventions? would the machines then let go of the inventions or would the machines use inventions and innovations as we humans often do to get power or some kinds of benefits? How would machines be able to handle dilemmas?

\section{CONCLUSION}

Reverting to the research question: What challenges may development and deployment of information systems including AI and AGI pose to the relationships between humans and machine? what did we find?

The relationships between man and man and between man and machine the relationships may be both a 'I-You' and an 'I-It' relationship depending on how the systems, machines are modelled and developed. Machines may be programmed using models of humans that attach the weaker points in the human nature and psyche to create an 'I-It' relationship without the user knowing or noticing it or trading hers/his use of 
the system as more valuable than being utilized by the system. Values are inscribed consciously in the systems/machines often without letting the users know. However, values are also often unconsciously inscribed in the systems through the modelling of the reality that the systems are to serve in. Through examples and statements made by central actors in large companies we find that humans are modelled as objects for the companies' business strategies for increasing sales, dominion, and profitmaking in the marked. Using Buber's, 'I-You', 'I-It' relationship models we argue that relationships between humans and relationships between humans and machines may be promoted or exploited through using information systems. Since there is no agreed upon ethical standards and the virtual country Internet is basically lawless actors in the marked are not hold responsible for what they do. What will happen in the future relationships where machines take the lead, may be an important and interesting research area including the questions of conscience and soul?

\section{ACKNOWLEDGEMENT}

Thanks to anonymous reviewers. Some of the suggestions are included in the paper, others may be used for expanding a future version of the paper being more specific about the human part of the relationships between man and machine.

\section{REFERENCES}

Bjørn-Andersen, N. (1980). Sosio-teknisk systemkontstruktion. Introduktion til Bjørn-Andersen. Niels (ed.): Artikelsamling til socio-teknisk systemkonstruktion. IFA, Handelshøjskolen i København. Samfundslitteratur.

Brooks, F. and Kugler, HJ. (1987). No Silver Bullet - Essence and Accident in Software Engineering.

Canales, K. and Sonnemaker, T. (2020 read 27.08.2020). https://www.businessinsider.com/amazon-ceo-jeff-bezos-networth-passes-200-billion-2020-8? $\mathrm{r}=\mathrm{US} \& \mathrm{IR}=\mathrm{T}$

Chatfield, T. (read 01.09.20) https://onezero.medium.com/theres-no-such-thing-as-ethical-a-i-38891899261d

Cox, C. (2019, red 27.08.2020). https://www.wired.com/story/chris-cox-leaving-facebook/

Du Pan (Undated, read 27.08.2020). https://en.wikipedia.org/wiki/French_Revolution

Iivari, J. et al. (1998). "A paradigmatic analysis contrasting information systems development approaches and methodologies." Information Systems Research 9(2): 164-193.

Lange, O. (1965). Wholes and Parts. Pergamon Press-PWN. Warsaw

McGregor, D. (1960). https://switcheducation.com/wp-content/uploads/2017/06/SEB_LYO_McGregor_Thinker.pdf

Nurminen, M.I. (1988), People or Computers: Three ways of looking at Information Systems. Studentlitteratur, Lund

Parker, S. (2017, 9. Nov read 27.08.2020). https://www.cbsnews.com/news/sean-parker-facebook-takes-advantage-ofvulnerability-in-human-psychology/

Postman, N. (1985). Amusing Ourselves to Death: Public Discourse in the Age of Show Business. USA: Penguin.

Sætra, H.S. (2019). Man and His Fellow Machines: An Exploration of the Elusive Boundary Between Man and Other Beings. In book: Discussing Borders, Escaping Traps (pp.215-228) Publisher: Waxmann

Thunberg, A-M. et al. (1982). Samverkansspiralen; Menniskan i informations - och kommunikationssamhellet. LuberFørlag, Stockholm

Walton, R. E. (1989) Up and running: integrating information technology and the organization. Harvard Business School Press, Boston, Mass.

Wang, A.B (2017, Dec 12, read 27.08.2020). https://www.washingtonpost.com/news/the-switch/wp/2017/12/12/formerfacebook-vp-says-social-media-is-destroying-society-with-dopamine-driven-feedback-loops/

$\begin{array}{ccc}\text { Wodehouse, } & \text { H. } & (1945) . \\ \text { https://scholar.google.com/scholar?hl=no\&as_sdt=0\%2C5\&q=helen+wodehouse+1945\&btnG= }\end{array}$

Zuboff, S. (1988). In the Age of the Smart Machine. The Future of Work and Power. Butterworth-Heinemann 1988

Zuboff, S. (2019). The Age of Surveillance Capitalism. The Fight for a Human Future at the New Frontier of Power. Profile Books Ltd., London 